\title{
Hidden superpowers
}

\author{
Christoph Haller, MD
}

\footnotetext{
From the Department of Cardiovascular Surgery, The Labatt Family Heart Centre, The Hospital for Sick Children, University of Toronto, Toronto, Ontario, Canada.

Disclosures: Author has nothing to disclose with regard to commercial support.

Received for publication Nov 23, 2017; accepted for publication Dec 4, 2017; available ahead of print Jan 6, 2018 Address for reprints: Christoph Haller, MD, Division of Cardiovascular Surgery, The Hospital for Sick Children,

555 University Ave, Toronto, Ontario, Canada M5G 1X8 (E-mail: christoph.haller@sickkids.ca).

J Thorac Cardiovasc Surg 2018;155:1195-6

$0022-5223 / \$ 36.00$

Copyright (C 2017 by The American Association for Thoracic Surgery

https://doi.org/10.1016/j.jtcvs.2017.12.027
}

The Fontan physiology is considered the best palliation for patients with congenital cardiac malformations that are unsuitable for biventricular repair. However, as the term implies, palliation means there is no cure, and life expectancy is limited. In this issue of the Journal, Cordina and colleagues ${ }^{1}$ suggest that Super-Fontans walk among us who perform exceptionally well. The analysis of the Australian and New Zealand Fontan Registry follows an interesting concept and looks at an isolated subgroup of patients with single-ventricle physiology after Fontan completion who have a maximum oxygen uptake and maximum workload of $\geq 80 \%$ predicted on exercise testing.

The group of patients presented by Cordina and colleagues who underwent Fontan palliation is highly selected. Only patients older than 16 years and with proof of high performance on cardiopulmonary exercise testing were included. Therefore, the cohort has undergone a significant selection process, and patients have had stable Fontan physiology for years. The authors conclude that there might be potentially modifiable extracardiac factors that contribute to the excellent performance of this group of singleventricle patients.

Although it is encouraging to see that some of these patients can lead a normal life, it is difficult to draw meaningful conclusions, especially as the results are descriptive and lack a control group. It is certainly striking that only 1 patient had a predominant right ventricular morphology. However, it would be premature to infer that it is the ventricular function alone that leads to the exceptional performance of these fortunate few. The close relationship between pulmonary vasculature, ventricular preload, and cardiac output is well described and indicates how complexly interwoven the various components of the single-ventricle physiology are., , $^{2,3}$

In a patient who has undergone Fontan palliation with preserved ventricular function, pulmonary vascular resistance is the most important limitation to changes in cardiac output. Especially during exercise, pulmonary blood flow cannot be adequately increased because of the lack of a subpulmonary ventricle and greater pulmonary arterial pressures, which result in diminished ventricular preload and suboptimal cardiac output. Therefore, patients who have

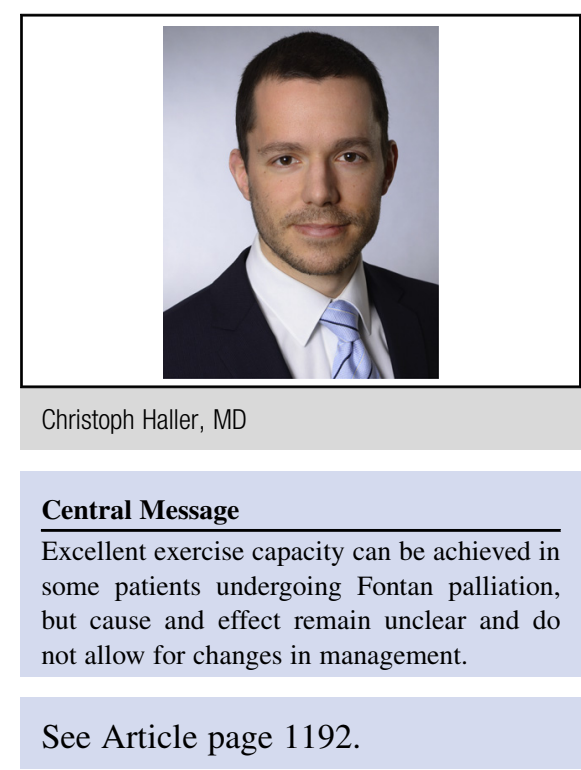

undergone Fontan palliation are expected to have lower cardiac output at rest and during exercise, ${ }^{4}$ and additional factors must contribute to allow for the near-normal exercise testing in this cohort. Unfortunately, there is little information on pulmonary vascular resistance or transpulmonary pressure, but it has to be assumed that these patients have characteristics that lead to low resistance, sustained endothelial function in the pulmonary circulation, and a better distribution of pulmonary flow that ensure adaptation of transpulmonary blood flow during exercise and thereby sufficient preloading to increase cardiac output. Furthermore, peripheral oxygen consumption may be more efficient.

It has been shown that training leads to improved exercise capacity in patients who have undergone Fontan palliation. ${ }^{5}$ Autologous preloading in physically active patients may lead to recruitment of the chronically deprived ventricle and counteract the gradual decline in ventricular function. However, if the high functional level of these patients who have undergone Fontan palliation should be ascribed to vigorous exercise, it must be interpreted carefully. Physical activity levels do not correlate with exercise capacity or social functioning. ${ }^{6}$ High maximum oxygen uptake can also be affected by components outside of the common oxygen delivery, cardiorespiratory, exercise axis, such as the individual perception of exertion, and cerebral regulation. ${ }^{7,8}$ Without thorough statistical analysis and consideration of a multitude of additional factors, the data do not allow for differentiation between cause and effect. The sobering aspect, nonetheless, is the lack of modifiable factors that we could use to improve the circulation. Surgical 
approach and interventions vary among patients, and we are left without knowing in which way management contributed to the outstanding wellbeing of these patients.

\section{References}

1. Cordina R, Du Plessis K, Tran D, D'Udekem Y. Super-Fontan: is it possible? J Thorac Cardiovasc Surg. 2018;155:1192-4.

2. Gewillig M, Brown SC. The Fontan circulation after 45 years: update in physiology. Heart. 2016;102:1081-6.

3. La Gerche A, Gewillig M. What limits cardiac performance during exercise in normal subjects and in healthy Fontan patients? Int J Pediatr. 2010;2010:1-8.
4. Ohuchi H. Cardiopulmonary response to exercise in patients with the Fontan circulation. Cardiol Young. 2005;15(suppl 3):39-44.

5. Sutherland N, Jones B, d'Udekem Y. Should we recommend exercise after the fontan procedure? Hear Lung Circ. 2015;24:753-68.

6. McCrindle BW, Williams RV, Mital S, Clark BJ, Russell JL, Klein G, et al. Physical activity levels in children and adolescents are reduced after the Fontan procedure, independent of exercise capacity, and are associated with lower perceived general health. Arch Dis Child. 2007;92:509-14.

7. Smirmaul BPC, Bertucci DR, Teixeira IP. Is the VO2max that we measure really maximal? Front Physiol. 2013;4:203.

8. Beltrami FG, Froyd C, Mauger AR, Metcalfe AJ, Marino F, Noakes TD. Conventional testing methods produce submaximal values of maximum oxygen consumption. Br J Sports Med. 2012;46:23-9. 